\title{
A Comparison of the Morbidities Associated with Different Early Treatments in Tubo-Ovarian Abscess Patients
}

\author{
Sumanta SAHA ${ }^{1}$, Sujata SAHA ${ }^{2}$
}

Chennai, India

\begin{abstract}
OBJECTIVE: A tubo-ovarian abscess needs hospitalization and early treatment with parenteral antibiotics only or along with imaging-guided drainage. This meta-analysis juxtaposes between these interventions - the length of stay in hospital in days, surgery requirement for those not responding to the initial treatment, and readmission.

STUDY DESIGN: The eligible papers searched in various databases (PubMed, Central, Embase, and Scopus) irrespective of their language or date of publication. The Joanna Briggs Institute's Critical Appraisal tool and Cochrane collaboration tool were used to appraise observational and randomized controlled trials, respectively. When a comparable outcome was reported from at least three studies of similar study design, they were included in the meta-analysis (fixed-effect model). Otherwise, outcomes were reported narratively.

RESULTS: From 164 studies, five eligible papers (four non-randomized studies and one randomized controlled trials) were reviewed. These studies sourced data from 609 tubo-ovarian abscess patients. Overall, all studies had at least one unclear risk of bias components. The length of stay in the hospital among the tubo-ovarian abscess patients favored the initial parenteral antibiotic only treatment $(\mathrm{WMD}=$ $-3.26 ; 95 \% \mathrm{Cl}=-4.93$ to $-1.58 ; \mathrm{p}<0.001 ; \mathrm{I}^{2}=80.9 \%$; $\mathrm{p}$-value of Cochranes $\mathrm{Q}=0.005$ ); however, on sensitivity analysis (meta-analysis with random-effect model) this difference disappeared. Less than three studies of a particular study design reported each of the remaining outcomes.
\end{abstract}

CONCLUSION: The current evidence on how these outcomes vary between the juxtaposed interventions received by the tubo-ovarian abscess patients remains inconclusive due to the inadequate number of good quality randomized controlled trials

Keywords: Abscess, Anti-bacterial agents, Drainage, Pelvic Inflammatory diseases, Radiography, Ultrasonography

Gynecol Obstet Reprod Med 2022;28(2):190-197

\section{Introduction}

A tubo-ovarian abscess (TOA) is a serious complication of pelvic inflammatory disease (PID) (1-3). It occurs in 15-30\% of women hospitalised with PID $(1,2)$. It causes the formation of pus and inflammatory mass (of the fallopian tube and (or) ovary) which often manifests clinically as abdominal pain,

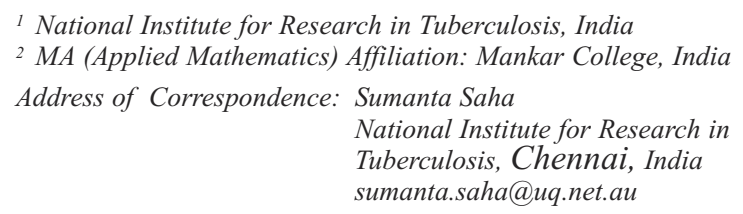

Submitted for Publication: 31.03.2020 Revised for Publication: 14.04.2020

Accepted for Publication: 02.05.2020 Online Published: 20.05.2020

ORCID IDs of the authors: $\quad$ SS : 0000-0003-0996-8846, $S S^{2}: 0000-0003-2009-6786$

\begin{tabular}{|c|c|}
\hline \multirow{3}{*}{ 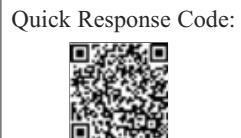 } & Access this article online \\
\hline & $\begin{array}{l}\text { Website: www.gorm.com.tr } \\
\text { e- mail: info@gorm.com.tr }\end{array}$ \\
\hline & DOI:10.201613/GORM.2020.1094 \\
\hline
\end{tabular}

How to cite this article: Saha $S^{I}$. Saha $S^{2}$. A comparison of the Morbidities Associated with Different Early Treatments in Tubo-Ovarian Abscess Patients. Gynecol Obstet Reprod Med. 2022;28(2):190-197 pelvic mass, fever, and leucocytosis $(1,3)$. It can sometimes be life-threatening when accompanied by the risk of rupture and consequent severe sepsis $(1,3)$.

To prevent these morbidities and mortality, TOA patients require an early hospitalisation and inpatient care with parenteral antibiotics (often considered as the first-line management) or dual therapy with parenteral antibiotics and imagingguided drainage (ultrasonography (US) or computed tomography (CT) guided chiefly) (1,3-5).

Due to the polymicrobial nature of the disease, administration of broad-spectrum parenteral antibiotics are vital $(1,2)$. Cefotetan, cefoxitin, doxycycline, ampicillin, gentamycin, and clindamycin are some of the frequently used antibiotics (3). The therapeutic success with parenteral antibiotics depends on the antibiotics' ability to penetrate, and remain within the abscess cavity and work against the microbes (1). Unresponsive TOA patients generally require surgery (e.g., drainage of the abscess, salpingo-oophorectomy or pelvic clearance) $(1,6)$. Almost three out of 10 antibiotic-treated TOA patients require a surgical intervention (2). 
Like the initial parenteral antibiotics only treatment, researchers have demonstrated the usefulness of early use of the above-mentioned dual therapy in TOA patients $(1,3,4)$. In a study of 302 women with TOA, the latter depicted a nominal need (in about $7 \%$ only) of subsequent surgery (4). The relatively low invasiveness of the drainage makes this dual therapy a well-tolerated treatment for TOA patients (1). Common routes of TOA drainage by this method are transvaginal and transrectal (7).

Since, both of these treatment modalities require inpatient care, it is important to understand the trade-off between them in terms of the required length of stay in hospital (LOS). While an increase in LOS can raise the risk of unwanted healthcare expenditure and hospital-acquired infections, premature discharges, on the other hand, might hinder the achievement of the desired health outcome and increase the number of emergency room presentations and readmissions.(8-12) So, a proper insight of inpatient LOS for particular illnesses is essential along with its comparison between different therapeutic modalities.

Therefore, this meta-analysis aimed to compare the average LOS between early inpatient treatment with parenteral antibiotics only and as an adjunct to imaging-guided drainage in TOA patients. Additionally, the need for surgery and readmission before and after discharge from the hospital were explored respectively.

\section{Material and Method}

The eligibility criteria for inclusion of studies comprised of the following features- 1 . TOA patients of any age who received the initial treatment inpatient. 2. Inpatient early treatment should have been compared between parenteral antibiotic/s (irrespective of regimen or dosage or duration of administration) and a combination of parenteral antibiotic/s and imaging-guided (US or CT or both) drainage (primary or salvage done by any route like transabdominal, transvaginal etc.) for the outcomes stated below. 3. Randomised controlled trials (RCT) and non-randomised studies (NRS) were eligible for inclusion. 4. For the respective interventions, the studies should have reported the LOS (in the hospital) in days (the primary outcome). A pre-registered protocol is unavailable for this review.

Succeeding ancillary outcomes in each of the treatment groups, when reported, were also studied- the number of TOA patients who underwent surgery due to failure of the initial inpatient intervention and the frequency of readmission with TOA post-discharge from the hospital. These secondary outcomes were not part of the eligibility criteria.

The definition of TOA and treatment failure was accepted as per the investigators. Surgical removal of an abscess (except by imaging-guided drainage or aspiration) along with the removal of adnexa, uterus, parts of bowel or pelvic clearance was considered as a surgical intervention.
Eligible papers' title and abstract were searched in the following electronic databases with no restriction to languagePubMed, CENTRAL, Embase, and Scopus. An additional search incorporated the bibliography of the papers read in full text. The initial search was done in April 2019. The last date of the repeat PubMed search was 30 March 2020. Following search terms were used for the database searches - TOA or pyosalpinx OR ovarian OR "tubo-ovarian" OR tuboovarian AND drain* OR aspirat* OR transabdominal OR transvaginal AND ultrasonograph* OR ultrasound OR imaging OR “computed tomography" OR CT OR scan AND antibiotic* OR antimicrobial. No filters were applied to narrow down the search. The literature search was not restricted to any date range.

The study selection process closely adhered to the steps commended in the PRISMA flow diagram.(13) The searched output of the electronic database was skimmed through while matching the eligibility criteria of this review. Papers seeming eligible or doubtful for inclusion were selected for full-text reading by the authors. Then, the first author extracted the following data from the papers included in this review, which was subsequently evaluated by the co-author for any unintended errors- 1. study profile (first author's last name, year of publication, and country where the study was conducted) 2 . study population's information (diagnosis with which patients were admitted, sample size, number of participants in each treatment group, the mean age of study population, inclusion and exclusion criteria, the frequency of attrition before discharge from hospital, and participant consent information). 3. study design 4 . intervention received by the treatment groups. 5. the outcomes of interest. The authors of the reviewed papers were not contacted.

Thenceforth, the authors independently assessed the risk of bias in the NRS and RCT, using The Joanna Briggs Institute's Critical Appraisal tool and Cochrane collaboration's tool, respectively. $(14,15)$ Conflict of opinion between the authors was resolved by discussion.

The effect of the two interventions was compared metaanalytically when at least three studies (that are not prone to high risk of bias) reported a statistically comparable outcome data. Data from NRS and RCT were not combined (for metaanalysis).

For LOS, a fixed-effect model was used for the meta-analysis as the compared NRS studies were relatively homogenous (e.g., retrospective cohort study design, conducted in the US, study population's mean age, and the antibiotics used). Furthermore, as the duration of inpatient stay was reported in the same unit (days), weighted mean difference (WMD) between the intervention groups was estimated using the inverse-variance method.(15) Statistical significance of effect estimates was determined at $\mathrm{p}<0.05$ and $95 \%$ confidence interval. Heterogeneity was reported with p-value of Cochrane's Q (statistically significant if $<0.1$ ) and $\mathrm{I}^{2}$ statistics (unimportant $(0-40 \%)$, moderate (30-60\%), substantial (50-90\%), and 
considerable (75-100\%)) (15). Publication bias was assessed visually using funnel plots. A sensitivity analysis repeated the meta-analysis with a random-effect model and also determined the predictive interval.

For the remaining outcomes, less than three studies were available to compare; therefore, we reported the findings narratively. Likewise, for the RCT, due to lack of additional comparable data from same study design, all of its outcome were reported qualitatively.

All statistical analysis was done with Stata statistical software (StataCorp, College Station, Texas, USA). This paper's reporting follows PRISMA reporting guideline (13).

\section{Results}

The database search produced 164 results (42 PubMed, 87 Scopus, 34 EMBASE, and 1 CENTRAL). Manual search did not retrieve any additional record. After removing the duplicates, we skimmed through 132 titles and abstracts and selected 14 articles for full-text reading. Finally, five articles (published between 1996 and 2016) meeting the eligibility criteria were incorporated in this review (16-20). Figure 1 depicts the study selection process.

Regarding the characteristics of the included studies, table I

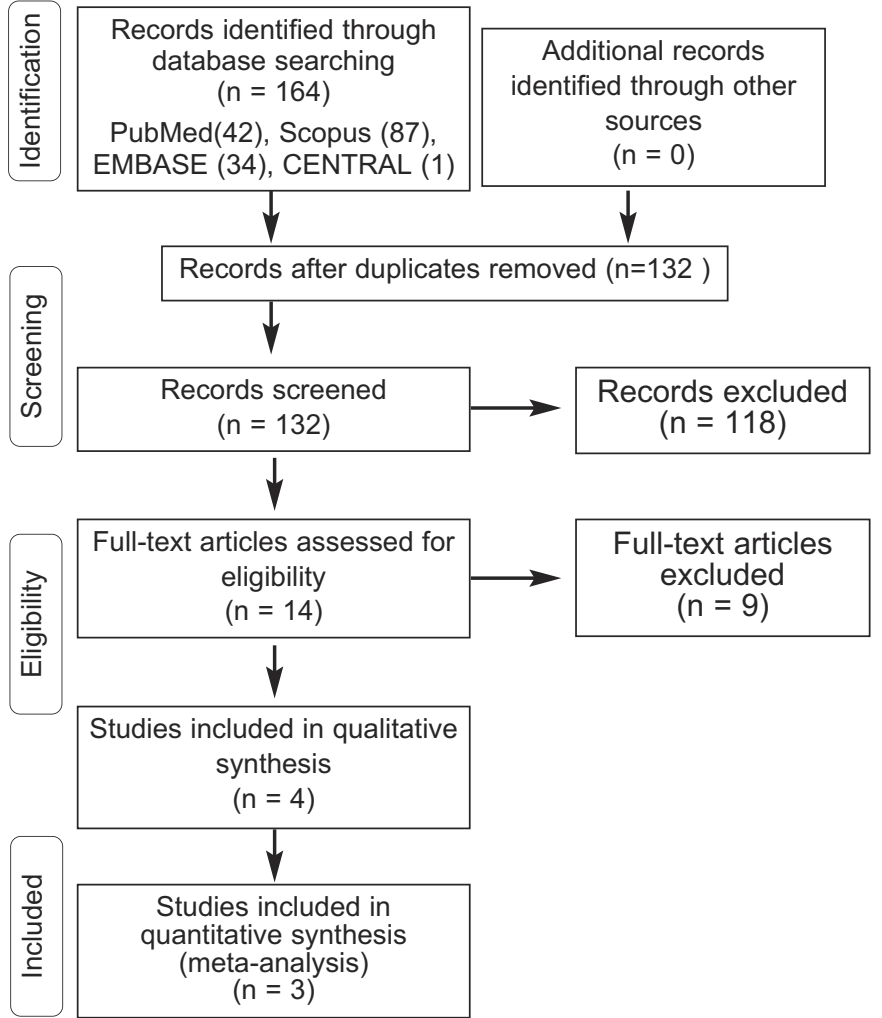

Figure 1: PRISMA 2009 Flow Diagram (From (22))

Table I: Summary data from the reviewed studies

\begin{tabular}{|c|c|c|c|}
\hline \multicolumn{4}{|c|}{ Summary of study population, study design, and intervention } \\
\hline $\begin{array}{l}\text { Author, } \\
\text { Year, } \\
\text { Country }\end{array}$ & Population & $\begin{array}{l}\text { Study } \\
\text { design }\end{array}$ & Intervention \\
\hline $\begin{array}{l}\text { Goharkha } \\
\text { y, } \\
2007, \\
\text { USA(18) }\end{array}$ & $\begin{array}{l}\text { Patients diagnosed and admitted with TOA be- } \\
\text { tween April } 1999 \text { and September } 2001 ; \text { sample } \\
\text { size=58; treated with antibiotics only initially=50; } \\
\text { treated with imaging-guided drainage (primary } \\
\text { type) initially=8; age=mean 31.7, range=16-61; in- } \\
\text { clusion and exclusion criteria: not clear; attrition be- } \\
\text { fore discharge from hospital: nil; consent from par- } \\
\text { ticipants: not clear }\end{array}$ & $\begin{array}{l}\text { Retrospective } \\
\text { cohort }\end{array}$ & $\begin{array}{l}\text { Intervention groups=2; group 1- iv antibiotics plus } \\
\text { primary or salvage image (CT or US) guided } \\
\text { drainage (draining by transvaginal } \\
\text { or transabdominal approach through a needle; } \\
\text { drainage decision based on clinical judgment of at- } \\
\text { tending physician); group 2- received iv antibiotics } \\
\text { only (antibiotic regimen: all patients received the } \\
\text { same: intravenous gentamicin and clindamycin. } \\
\text { ampicillin was given when not penicillin-allergic). }\end{array}$ \\
\hline $\begin{array}{l}\text { To, 2014, } \\
\text { USA(19) }\end{array}$ & $\begin{array}{l}\text { Patients diagnosed with TOA between } 1998 \text { to } \\
2008 \text {; sample size=240; treated with antibi- } \\
\text { otics=199; treated with imaging-guided drainage } \\
\text { initially }=41 \text {; mean age }=32.61 \text {; inclusion criteria: } \\
11-49 \text { years old females, admitted with ICD-9 code } \\
614 . x \text { who were treated with either antibiotic initially } \\
\text { or imaging-guided drainage (primary or sec- } \\
\text { ondary); exclusion criteria: pregnancy, malignancy, } \\
\text { lack of previous evidence of abscess radiologically } \\
\text { during surgery, drainage performed due to cause } \\
\text { other than abscess, and no history of hysterectomy } \\
\text { or bilateral salpingo-oophorectomy; attrition before } \\
\text { discharge from hospital: nil; consent from partici- } \\
\text { pants: obtained }\end{array}$ & $\begin{array}{l}\text { Retrospective } \\
\text { cohort }\end{array}$ & $\begin{array}{l}\text { Intervention groups=2; group 1- iv antibiotics and } \\
\text { primary or salvage image-guided drainage (CT } \\
\text { guided); group 2- iv antibiotics treated (mainly re- } \\
\text { ceived ampicillin, gentamicin, and clindamycin (or } \\
\text { metronidazole)). }\end{array}$ \\
\hline $\begin{array}{l}\text { Crespo, } \\
2014, \\
\text { USA (16) }\end{array}$ & $\begin{array}{l}\text { Patients diagnosed and admitted with TOA be- } \\
\text { tween 2007-12; sample size=158; information } \\
\text { missing=10; analyzed=148; treated with antibiotics } \\
\text { only initially=108; treated with imaging-guided } \\
\text { drainage initially=29; mean age }=37.39 \text { years } \\
\text { ( } n=158) \text {; inclusion criteria: unclear; exclusion crite- } \\
\text { ria: }<18 \text { years of age, pregnancy, previous admis- } \\
\text { sion due to pelvic inflammatory disease; attrition } \\
\text { before discharge from hospital: nil; consent from } \\
\text { participants: unclear }\end{array}$ & $\begin{array}{l}\text { Retrospective } \\
\text { cohort }\end{array}$ & $\begin{array}{l}\text { Intervention groups=3; group 1- initially receiving } \\
\text { antibiotic treatment only (commonly used antibi- } \\
\text { otics- gentamicin plus clindamycin, cefoxitin plus } \\
\text { doxycycline, and a triple antibiotic regimen (ampi- } \\
\text { cillin, gentamicin, and clindamycin)); group 2- iv an- } \\
\text { tibiotics plus US-guided drainage; group } 3 \text { - surgi- } \\
\text { cal intervention }\end{array}$ \\
\hline
\end{tabular}




\begin{tabular}{|c|c|c|c|c|c|c|c|}
\hline $\begin{array}{l}\text { Farid, } \\
2016, \\
\text { USA (17) }\end{array}$ & \multicolumn{3}{|c|}{$\begin{array}{l}\text { Patients diagnosed and admitted with TOA be- } \\
\text { tween 2001-12; sample size=113 (met inclusion } \\
\text { criteria); treated with antibiotics only initially=61; } \\
\text { treated with iv antibiotics and imaging-guided } \\
\text { drainage initially=26; treated with iv antibiotics and } \\
\text { surgery=26; mean age=40.4 years; inclusion crite- } \\
\text { ria: TOA diagnosed based on imaging and clinical } \\
\text { criteria and patients admitted more than } 24 \text { hours } \\
\text { for treatment; exclusion criteria: TOA diagnosis not } \\
\text { matching imaging or clinical diagnostic criteria and } \\
\text { non-consenting participants; attrition before dis- } \\
\text { charge from hospital: nil; consent from participants: } \\
\text { obtained }\end{array}$} & 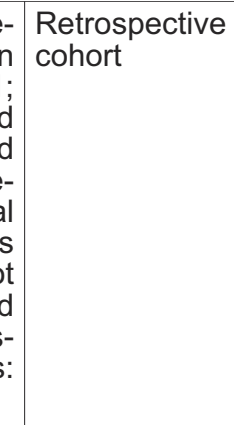 & \multicolumn{3}{|c|}{$\begin{array}{l}\text { ntervention groups=4; group 1-received iv antibi- } \\
\text { otics only; group } 2 \text { - received iv antibiotics and } \\
\text { imaging-guided drainage; group 3-received iv an- } \\
\text { tibiotics and initial surgical intervention only; group } \\
\text { 4- those failed to respond to antibiotic therapy only } \\
\text { were treated with imaging-guided drainage; all pa- } \\
\text { tients received antibiotics and the common regi- } \\
\text { ments were-gentamicin/clindamycin, second-gen- } \\
\text { eration cephalosporins/doxycycline/metronidazole, } \\
\text { fluoroquinolone/metronidazole, and aminopeni- } \\
\text { cillin/fluoroquinolone/metronidazole }\end{array}$} \\
\hline $\begin{array}{l}\text { Perez- } \\
\text { Medina, } \\
\text { 1996, } \\
\text { Spain(20) }\end{array}$ & \multicolumn{3}{|c|}{$\begin{array}{l}\text { Patients diagnosed with TOA; sample size }=40 \text {; } \\
\text { treated with antibiotics only initially }=20 ; \text { treated } \\
\text { with imaging-guided drainage initially }=20 ; \text { mean } \\
\text { age }=29 \text { (range } 16-49 \text { years); inclusion and exclu- } \\
\text { sion criteria: not clear; attrition before discharge } \\
\text { from hospital: nil; consent from participants: ob- } \\
\text { tained }\end{array}$} & 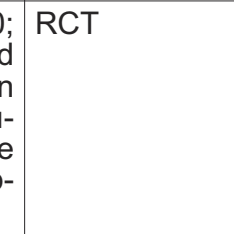 & \multicolumn{3}{|c|}{$\begin{array}{l}\text { Intervention groups }=2 \text {; group } 1 \text { - antibiotics only } \\
\text { group } 2 \text { - antibiotics and imaging-guided drainage } \\
\text { both intervention groups received clindamycin and } \\
\text { gentamicin }\end{array}$} \\
\hline \multicolumn{8}{|c|}{ Summary of primary and secondary outcome data } \\
\hline \multicolumn{8}{|c|}{ Outcome: duration of hospital stays } \\
\hline \multirow{2}{*}{\multicolumn{2}{|c|}{$\begin{array}{l}\text { Study (first author's } \\
\text { last name, year) }\end{array}$}} & \multicolumn{3}{|c|}{ Antibiotic group } & \multicolumn{3}{|c|}{ Imaging-guided drainage group } \\
\hline & & Sample size $(n)$ & Mean (in days) & SD (in days) & Sample size $(n)$ & Mean (in days) & SD (in days) \\
\hline \multicolumn{2}{|c|}{ Goharkhay, 2007(18) } & \multicolumn{6}{|c|}{ Median data, hence, data could not be pooled for meta-analysis. } \\
\hline \multicolumn{2}{|c|}{$\begin{array}{l}\text { To, } 2014(19) \\
\text { Crespo, } 2014(16) \\
\text { Farid, } 2016(17) \\
\text { Perez-Medina,1996 (20) }\end{array}$} & $\begin{array}{l}199 \\
109 \\
61 \\
20\end{array}$ & $\begin{array}{l}7.4 \\
5.59 \\
5.79 \\
3.9\end{array}$ & $\begin{array}{l}6.1 \\
2.52 \\
11.6 \\
\text { Not available }\end{array}$ & $\begin{array}{l}41 \\
30 \\
26 \\
20\end{array}$ & $\begin{array}{l}13.3 \\
9.63 \\
4.85 \\
9.1\end{array}$ & $\begin{array}{l}8.9 \\
7.58 \\
3.02 \\
\text { Not available }\end{array}$ \\
\hline \multicolumn{8}{|c|}{ Outcome: surgery required versus surgery not required } \\
\hline \multirow{2}{*}{\multicolumn{2}{|c|}{$\begin{array}{l}\text { Study (first author's } \\
\text { last name, year) }\end{array}$}} & \multicolumn{3}{|c|}{ Antibiotic group } & \multicolumn{3}{|c|}{ Imaging-guided drainage group } \\
\hline & & $\begin{array}{l}\text { Sample size } \\
(\mathrm{n})\end{array}$ & $\begin{array}{l}\text { Surgery } \\
\text { required }\end{array}$ & $\begin{array}{l}\text { Surgery not } \\
\text { required }\end{array}$ & $\begin{array}{l}\text { Sample size } \\
(\mathrm{n})\end{array}$ & $\begin{array}{l}\text { Surgery } \\
\text { required }\end{array}$ & $\begin{array}{l}\text { surgery not } \\
\text { required }\end{array}$ \\
\hline $\begin{array}{l}\text { Goharkha) } \\
\text { To, 2014 } \\
\text { Perez-Mec }\end{array}$ & $\begin{array}{l}y, 2007(18) \\
(19) \\
\text { dina, } 1996(20)\end{array}$ & $\begin{array}{l}50 \\
199 \\
20\end{array}$ & $\begin{array}{l}3 \\
31 \\
6^{*}\end{array}$ & $\begin{array}{l}47 \\
168 \\
14\end{array}$ & $\begin{array}{l}8 \\
41 \\
20\end{array}$ & $\begin{array}{l}0 \\
1 \\
2\end{array}$ & $\begin{array}{l}8 \\
40 \\
18\end{array}$ \\
\hline \multicolumn{8}{|c|}{ Outcome: readmission required versus readmission not required } \\
\hline \multirow{2}{*}{\multicolumn{2}{|c|}{$\begin{array}{l}\text { Study (first author's } \\
\text { last name, year) }\end{array}$}} & Antibiotic group & & & \multicolumn{3}{|c|}{ Imaging-guided drainage group } \\
\hline & & Sample size $(\mathrm{n})$ & $\begin{array}{l}\text { Readmission } \\
\text { required }\end{array}$ & $\begin{array}{l}\text { Readmission } \\
\text { not required }\end{array}$ & Sample size (n) & $\begin{array}{l}\text { Readmission } \\
\text { required }\end{array}$ & $\begin{array}{l}\text { Readmission } \\
\text { not required }\end{array}$ \\
\hline $\begin{array}{l}\text { To, } 2014( \\
\text { Crespo, } 2\end{array}$ & $\begin{array}{l}(19) \\
014(16)\end{array}$ & $\begin{array}{l}199 \\
108\end{array}$ & $\begin{array}{l}45 \\
45\end{array}$ & $\begin{array}{l}154 \\
63\end{array}$ & $\begin{array}{l}41 \\
29\end{array}$ & 12 & $\begin{array}{l}29 \\
22\end{array}$ \\
\hline
\end{tabular}

IV: intravenous; CT: Computed tomography; RCT: Randomized controlled trials; SD: Standard deviation; TOA: Tubo-ovarian abscess; US: Ultrasonography

illustrates their salient features. In total, about 609 TOA patients were recruited ( $93 \%$ from the US and remaining from Spain) (16-20). The mean age of the population was 35 years (16-20). Between hospital admission to discharge, among the intervention groups of interest, there was no attrition in sample size across the studies (16-20). Among the five studies, four (US-based) (16-19) were of NRS design (retrospective cohort studies) and one (from Spain) (20) was RCT.

In TOA patients, all studies compared the following inpatient introductory therapies- parenteral antibiotic treatments only versus imaging-guided drainage as a conjunct therapy (16-20). All studies compared the LOS in the hospital between the two treatment groups (16-20). Clindamycin and gen- tamycin were the two antibiotics reported to be used by all of the studies (16-0). Only three studies (two NRS and one RCT) reported the requirement of surgeries before discharge from the hospital (due to non-response to initial inpatient treatment) (18-20). Two studies (NRS) reported the need for readmission after discharge from the hospital $(16,19)$.

Next, the risk of bias of the studies were assessed (Table2) (16-20). In the observational studies, the mechanism of confounder handling $(16,18,19)$ and exposure determination (16-19) (i.e., the rationale clinicians used to ascertain which participant receives which intervention) remained unclear. Additionally, the inter-rater or intra-rater reliability of the interventionists who performed the imaging-guided drainage 


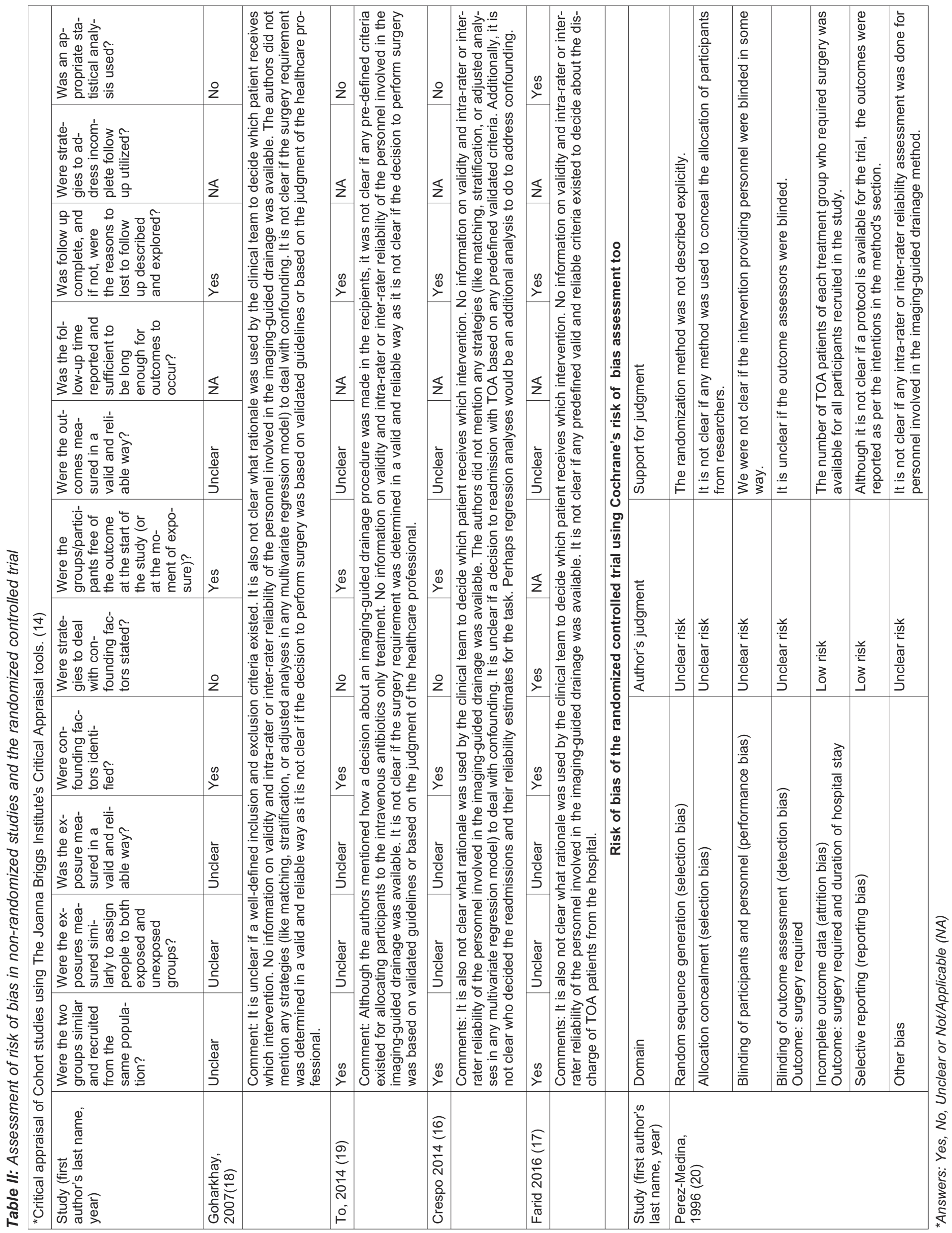


wasn't clear among NRS (16-19). The NRS (16-19) were at low risk of bias for the following components. None of these studies had attrition in their study population (until discharge from the hospitals)(16-19) and all identified a list of possible confounders at baseline (like age, sex) (16-19). Moreover, most NRS had mentioned about pre-defined eligibility criteria for recruiting study participants $(16,17,19)$ and were free of the outcome of interest at the participant recruitment stage of study $(16,18,19)$.

In the RCT (20), the risk of selection bias was unclear, since trialists did not mention the exact procedure used for randomization or concealing the allocation of interventions from the participants and from the researchers. Furthermore, it is unclear if the intervention providers and the outcome assessors were blind about the interventions received by the participants (20). The RCT was at low risk of attrition and reporting bias.(20) Summarizing the risk of bias across studies was difficult due to the differences in study designs (NRS versus RCT) (16-20). Overall, all studies had components of unclear risk of bias (16-20).

The primary and secondary outcome data from the respective studies are summarised in table 1 (16-20).

LOS: The primary outcome data were available from all of the studies (16-20). However, the Goharkhay et al. (2007) study (18) and the RCT(20) were not incorporated in the metaanalysis due to their reporting of median data and being the only interventional study available for a statistical comparison respectively. In contrast to the comparison group (median $=4.5$ days; range $=4-8$ ), in the Goharkhay et al. (2007) study(18), the LOS in the hospital was longer $(p<0.05)$ in the parenteral antibiotic-treated patients (median=7 days; range=4-16). Similarly, the parenteral antibiotic-treated group of the RCT remained inpatient for a statistically significantly $(p<0.001)$ longer duration (average 9.1 days) than the TOA patients who also received imaging-guided drainage as the initial treatment (mean 3.9 days) (20).

The LOS data from the remaining studies $(16,17,19)$ were compared meta-analytically. Meta-analysis using a fixed effect model favoured the treatment group receiving parenteral antibiotics only; however, there was considerable statistical heterogeneity $(\mathrm{WMD}=-3.26 ; 95 \% \mathrm{CI}=-4.93$ to $-1.58 ; p<0.001$; $\mathrm{I} 2=80.9 \%$; $p$-value of Cochranes $\mathrm{Q}=0.005$ ) (Figure $2 \mathrm{a}$ ). We could not rule out publication bias as the visual inspection of the funnel plot suggested asymmetry (Figure 2b).

The sensitivity analysis didn't replicate the findings of the preliminary meta-analysis. It did not find any statistically significant difference in LOS between the compared interventions $(\mathrm{WMD}=-3.053 ; 95 \% \mathrm{CI}=-6.90$ to $0.80 ; p=0.120)$ (Figure 2a). The predictive interval ( $95 \% \mathrm{CI}=-49.24$ to 43.13 ) suggested that a future study might find the combination therapy favorable in reducing the length of hospital stay than the parenteral antibiotics therapy only.

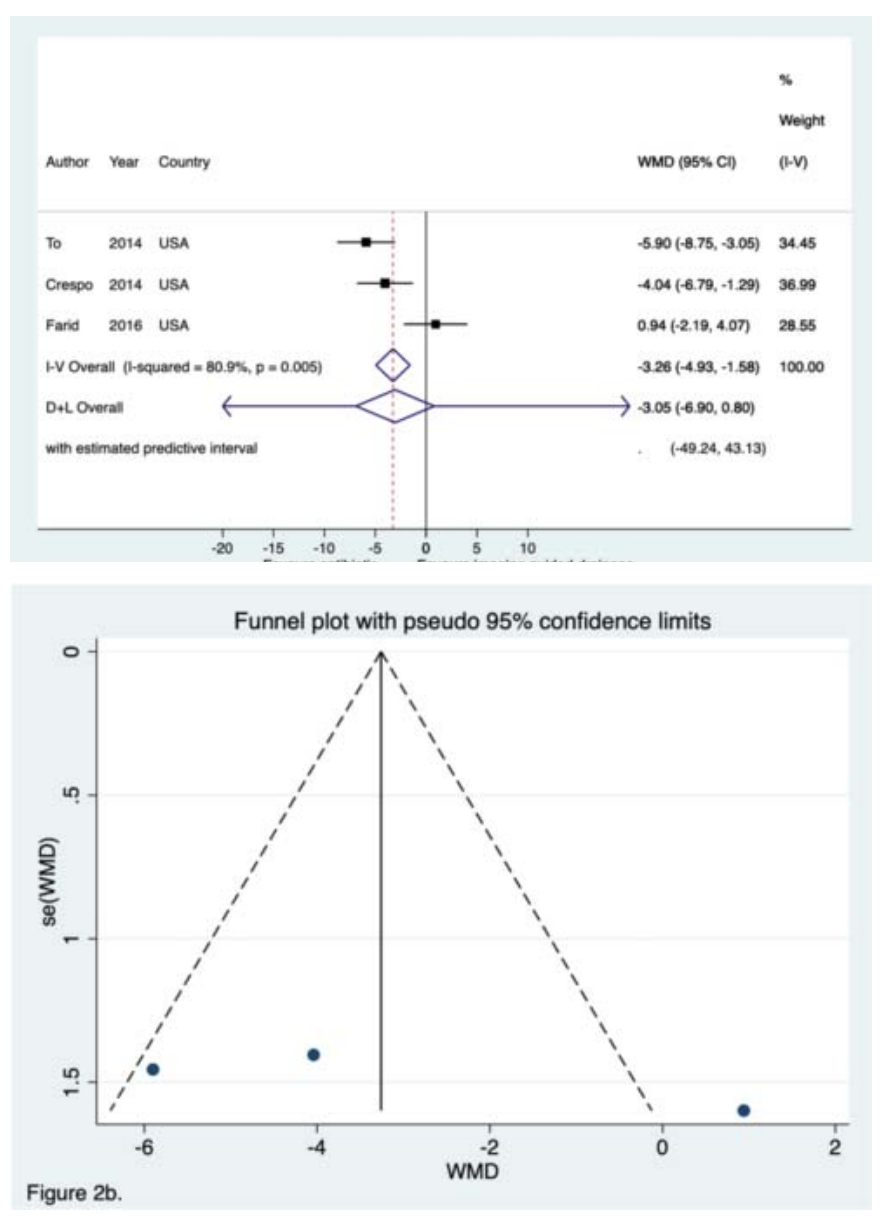

Figure 2: Forest plot (2a) and funnel plot (2b) for the comparison between initial inpatient treatment with parenteral antibiotic only and with imaging-guided drainage. Outcome: the duration of hospital stay (in days) $(16,17,19)$.

Surgery requirement: Data concerning the necessity of surgery upon the initial treatment failure was available from two NRS $(18,19)$ and the RCT $(20)$. Overall, surgery was more common in the parenteral antibiotics treated group $(15 \% ; 41 / 269)$ compared to patients who additionally received imaging-guided drainage $(4 \% ; 3 / 69)(18-20)$. The former treatment group most frequently underwent adnexectomy (almost $54 \%$; 22/41) followed by a combination of adnexectomy and hysterectomy (about 29\%;12/41); however, salpingectomy was the least used method $(2 \% ; 1 / 41)(18-20)$. The latter was treated with adnexectomy only or along with hysterectomy (18-20).

Readmissions: Two studies reported this outcome $(16,19)$. Taking together, the percentage of readmission was slightly larger in TOA patients administered with antibiotics only (29\%; 90/307) than patients who received an adjunct imagingguided intervention $(19 / 70 ; 27 \%)$.

\section{Discussion}

In summary, five research papers (four NRS (16-19) and one RCT) (20) published between 1996 and 2016 were reviewed. They sourced data from 609 participants with a mean 
age of 35 years. While the way of handling confounders and determining exposures was unclear among the NRS (16-19), the risk of selection bias, performance bias, and detection bias was not clear in the RCT (20), The meta-analytic comparison of LOS of three NRS $(16,17,19)$ is not robust as they are not replicable in sensitivity analysis and have considerable unexplained heterogeneity.

The quality of the LOS-related meta-analysis finding was determined using the GRADE approach proposed by the GRADE Working Group (2004) (21). The evidence was double downgraded to low-quality evidence because it came from studies of weaker epidemiological design (observational) with unexplained heterogeneity and unclear risk of bias.

To compare the findings of this paper with existing evidence in this background, different databases (PubMed, CENTRAL, and Prospero) were explored for any existing, registered, or ongoing reviews. However, no such reviews were available for contrasting. Henceforth, the key strength of this paper is its conceptual uniqueness. Besides, this review is likely to be comprehensive as the database search was not restricted to any language or date range.

The primary implication of this paper is that it identifies an area of gynecological research where there is a paucity of good quality RCTs which produces an evidence gap in the context. Future, trialists may find our study useful to plan better RCTs that can address this knowledge gap. Additionally, health care professionals like gynecologists and interventional radiologists may find this review as a brief overview of some of the aspects of TOA management.

Nonetheless, this review has certain limitations. Since the reviewed studies used different antibiotic dosages and regimens, we could not extricate if these played any role in the outcomes observed. Then, at the outcome level, it was not clear how the outcomes of interest were defined and measured by the reviewed studies (Table 2). Lastly, at the study level, most studies reviewed in this paper were of weaker study design (i.e., NRS) (16-19). The only RCT also suffered from certain weaknesses like small sample size, single-centric design, and unclear risk of biases (20).

\section{Conclusion}

The evidence regarding if the LOS, surgery requirement, and the frequency of readmission in TOA patients vary between the initial parenteral antibiotic therapy recipients and combined parenteral antibiotics and imaging-guided drainage recipients remain inconclusive. Presently, there is a critical shortage of adequately powered large multicentric RCTs addressing the context.

Acknowledgment: This study was conducted by the authors independently and not related to their affiliated institutions.
Funding: No funding was received for this work. Conflict Of Interest: None declared.

Author Contribution: SS1 contributed to the conception, design, database search, data extraction, critical appraisal, analysis, and drafting of the manuscript. SS2 critically appraised the reviewed papers and rechecked the extracted data, analysis, and manuscript draft.

\section{References}

1. Munro K, Gharaibeh A, Nagabushanam S, Martin C. Diagnosis and management of tubo-ovarian abscesses. Obstet Gynaecol. 2018;20(1):11-9.

2. McNeeley SG, Hendrix SL, Mazzoni MM, Kmak DC, Ransom SB. Medically sound, cost-effective treatment for pelvic inflammatory disease and tuboovarian abscess. Am J Obstet Gynecol. 1998;178(6):1272-8. Doi: 10.1111/ tog.12447. Doi: 10.1016/s0002-9378(98)70333-3.

3. Kairys N, Roepke C. Tubo-Ovarian Abscess. [Updated 2022 Jun 21]. In: StatPearls [Internet]. Treasure Island (FL): StatPearls Publishing; 2022 Jan-. Available from: https://www.ncbi.nlm.nih.gov/books/NBK448125/

4. Gjelland K, Ekerhovd E, Granberg S. Transvaginal ultrasound-guided aspiration for treatment of tubo-ovarian abscess: A study of 302 cases. Am J Obstet Gynecol. 2005; 193(4):1323-30. Doi: 10.1016/j.ajog.2005.06.019.

5. Silva F, Silva J, Rocha I, Brito T, Paredes E, Ramalho G, et al. Surgical approach of tubo-ovarian abscesses from theory to our minimally invasive practice. Gynecol Minim Invasive Ther. 2015;4(3):72-5. Doi: 10.1016/j.gmit. 2015.01.009.

6. Lareau SM, Beigi RH. Pelvic Inflammatory Disease and Tubo-ovarian Abscess. Infect Dis Clin North Am. 2008; 22(4):693-708. Doi: 10.1016/j.idc.2008.05.008.

7. Sudakoff GS, Lundeen SJ, Otterson MF. Transrectal and Transvaginal Sonographic Intervention of Infected Pelvic Fluid Collections. Ultrasound Q. 2005;21(3):175-85. Doi: 10.1097/01.ruq.0000174753.16708.7a.

8. Katz MH. Decreasing hospital costs while maintaining quality: can it be done? Arch Intern Med. 2010;170 (4):317-8. Doi: 10.1001/archinternmed.2009.519.

9. Ayanian JZ. The elusive quest for quality and cost savings in the Medicare program. JAMA. 2009;301(6):668-70. Doi: 10.1001/jama.2009.91.

10. McAlister FA, Bakal JA, Majumdar SR, Dean S, Padwal RS, Kassam N, et al. Safely and effectively reducing inpatient length of stay: a controlled study of the General Internal Medicine Care Transformation Initiative. BMJ Qual Saf. 2014;23(6):446-56. Doi: 10.1136/bmjqs-2013002289

11. Organisation for Economic Co-operation and Development. Health at a Glance 2017. OECD Publishing, Paris. OECD; 2017. (Health at a Glance). 
12. Hassan M, Tuckman HP, Patrick RH, Kountz DS, Kohn JL. Hospital length of stay and probability of acquiring infection. Int J Pharm Healthc Mark. 2010;4(4):324-38. Doi: $10.1108 / 17506121011095182$.

13. Liberati A, Altman DG, Tetzlaff J, Mulrow C, Gøtzsche PC, Ioannidis JPA, et al. The PRISMA statement for reporting systematic reviews and meta-analyses of studies that evaluate health care interventions: explanation and elaboration. J Clin Epidemiol. 2009;62(10):e1-e34. Doi: 10.1016/j.jclinepi.2009.06.006.

14. Moola S, Munn Z, Tufanaru C, Aromataris E, Sears K, Sfetcu R, et al. Chapter 7: Systematic reviews of etiology and risk. In: Aromataris E, Munn Z (Editors). Joanna Briggs Inst Rev Manual Joanna Briggs Inst. 2017; from: https://reviewersmanual.joannabriggs.org/.

15. Higgins JPT GS (editors). Cochrane Handbook for Systematic Reviews of Interventions Version 5.1.0. [Internet]. The Cochrane Collaboration. 2011. Available from: www.cochrane-handbook.org

16. Crespo FA, Ganesh D, Lo K, Chin K, Norris P, Chakhtoura N. Surgical, Ultrasound Guided Drainage, and Medical Management of Tuboovarian Abscesses. ISRN Infect Dis. 2014;2014:501729. Doi: 10.1155/ 2014/501729.

17. Farid H, Lau TC, Karmon AE, Styer AK. Clinical characteristics associated with antibiotic treatment failure for tu- boovarian abscesses. Infect Dis Obstet Gynecol. 2016;2016:5120293. Doi: 10.1155/2016/5120293.

18. Goharkhay N, Verma U, Maggiorotto F. Comparison of CT- or ultrasound-guided drainage with concomitant intravenous antibiotics vs. intravenous antibiotics alone in the management of tubo-ovarian abscesses. Ultrasound Obstet Gynecol. 2007;29(1):65-9. Doi: 10.1002/uog. 3890 .

19. To J, Aldape D, Frost A, Goldberg GL, Levie M, Chudnoff S. Image-guided drainage versus antibiotic-only treatment of pelvic abscesses: short-term and long-term outcomes. Fertil Steril. 2014;102(4):1155-9. Doi: 10. 1016/j.fertnstert.2014.06.025.

20. Perez-Medina T, Huertas MA, Bajo JM. Early ultrasoundguided transvaginal drainage of tuba-ovarian abscesses: a randomized study. Ultrasound Obstet Gynecol. 1996;7 (6):435-8. Doi: 10.1046/j.1469-0705.1996.07060435.x.

21. Atkins D, Best D, Briss PA, Eccles M, Falck-Ytter Y, Flottorp S, et al. Grading quality of evidence and strength of recommendations. BMJ. 2004;328(7454):1490. Doi: 10.1136/bmj.328.7454.1490.

22. Moher D, Liberati A, Tetzlaff J, Altman DG, The PRISMA Group. Preferred Reporting Items for Systematic Reviews and Meta-Analyses: The PRISMA Statement. PLoS Med. 2009;6(7):e1000097. Doi: 10. 1371/journal.pmed.1000097. 